\title{
Pemahaman Konsep Siswa melalui Model Inkuiri Terbimbing Berbantuan Simulasi PhET
}

\author{
A. A. Rais* , L. Hakim, dan Sulistiawati \\ Pendidikan Fisika, FKIP, Universitas PGRI Palembang, Indonesia \\ * email: ka.raees22@gmail.com
}

Received: November $2^{\text {nd }}, 2019$. Accepted: January 9 $9^{\text {th }}, 2020$. Published: February $2^{\text {th }}, 2020$

\begin{abstract}
Abstrak
Tujuan penelitian ini adalah untuk mengetahui pemahaman konsep siswa melalui model pembelajaran inkuiri terbimbing. Metode yang digunakkan adalah quasi eksperimen dengan desain posttest only control group. Populasi dalam penelitian ini adalah seluruh siswa kelas XI di salah satu SMA kota Palembang. Teknik pengambilan sampel menggunakan cluster random sampling. Sampel yang digunakan adalah kelas XI IPA 3 sebagai kelas eksperimen dan kelas XI IPA 4 sebagai kelas kontrol. Kedua kelas diberi tes akhir (posttest) setelah diterapkan model inkuiri di kelas eksperimen dan model direct instruction di kelas kontrol. Hasil penelitian menunjukan terdapat perbedaan pemahaman konsep siswa di kelas eksperimen dan kelas kontrol. Analisis hasil penelitian menggunakan uji hipotesis beda rata-rata kelas eksperimen dan kelas kontrol dengan menggunakan uji-t. Uji-t dilakukan dengan menggunakan SPSS 22 didapat hasil sig. (2tailled) sebesar 0,00. Hasil tersebut menunjukkan model inkuiri terbimbing memiliki pengaruh signifikan terhadap pemahaman konsep fisika.
\end{abstract}

\begin{abstract}
The purpose of this study is to understand students' concepts on indicators exemplifying the level of understanding of student concepts through guided inquiry. The population of this study was all grade XI students in one of the high schools in Palembang. This research is quantitative research. The results of understanding students' concepts can be seen from the results of the posttest of each class using t-test. Based on the results of the study showed there were differences between students in
\end{abstract}


the experimental class and the control class. This can be seen from the t-test using SPSS 22 obtained significant results $(2-$ tailled of 0.00 . These results indicate the guided inquiry model has an influence on understanding the concepts of physics. C2020PERJ

Keywords: Guided inquiry; concept understanding; PhET simulation.

\section{PENDAHULUAN}

Fisika merupakan salah satu cabang ilmu sains. Fisika telah dipelajari di tingkat Sekolah Menengah Atas (SMA) hingga ke perguruan tinggi atau universitas. Fisika merupakan ilmu yang mempelajari materi dan energi serta hubungan di antara keduanya (Kanginan, 2016).

Pada pembelajaran fisika, terdapat konsep-konsep yang bersifat abstrak yang tidak dapat diajarkan secara langsung; misalnya fisika atom, fisika kuantum, dan fisika zat padat (Kusdiastuti, Harjono, Sahidu \& Gunawan, 2017). Pembelajaran konsep-konsep abstrak tentunya membutuhkan media yang dapat menyajikan konsep abstrak menjadi lebih konkret. Media tersebut dapat berupa gambar, video, atau animasi sehingga konsep yang disajikan lebih jelas (Nurhalimah, Suhartono \& Cahyana, 2019). Dengan demikian pembelajaran fisika disesuaikan dengan karakteristik materi yang disampaikan (Rahayu, 2017; Arimbawa, Santyasa \& Rapi, 2017).

Pelaksanaan memerlukan pembelajaran sistematis agar konsep yang disajikan dapat diserap secara maksimal oleh siswa sehingga tujuan pembelajaran dapat dicapai (Sani, 2019). Konsep fisika dibangun dari hasil pengamatan dan eksperimen ahli. Pembelajaran fisika dapat dilakukan dengan menerapkan model pembelajaran yang melibatkan siswa secara aktif dan membimbing siswa melakukan penemuan, seperti model pembelajaran inkuiri.

Model inkuiri yang cocok untuk mengajarkan konsep fisika kepada siswa adalah model inkuiri terbimbing karena model ini menekankan keaktifan siswa dalam kegiatan pembelajaran (Lewa, Susanto \& Marwoto, 2017). Hal ini sesuai dengan pendapat Anam (2016) yang menyatakan bahwa pembelajaran konsep dan prinsip dasar materi fisika cocok menggunakan model inkuiri terbimbing.

Inkuiri terbimbing mengajak siswa untuk mencari jawaban dari permassalahan melalui kegiatan eksperimen yang dilakukan dengan bimbingan guru (Aeni, Supardi \& Kasmadi, 2017). Melalui pembelajaran inkuiri terbimbing, siswa aktif berperan serta dalam pelaksanan pembelajaran melalui 
kegiatan identifikasi massalah, membuat hipotesis, pengumpulan dan analisis data (Abdurrozak, Jayadinata \& Isrok'atun, 2016). Model inkuiri terbimbing memiliki beberapa keunggulan, antara lain: siswa berperan aktif dalam kegiatan pembelajaran, menumbuhkan serta menanamkan sikap keingintahuan, serta kemampuan siswa dalam memecahkan massalah menjadi lebih baik. Penerapan model Guided Discovery Learning berbantuan media simulasi PhET memberikan pengaruh terhadap pemahaman konsep Fisika siswa (Hidayat, Hakim, \& Lia, 2019). Langkahlangkah pembelajaran inkuiri terbimbing dapat membantu siswa menjadi lebih baik dalam memahami konsep fisika.

Siswa yang memahami materi dapat mengubah berbagai bentuk representasi menjadi bentuk lainnya, serta membaca tabel hasil penelitian sebagai penyajian data. Pemahaman konsep akan memberikan bekal kepada siswa untuk beradaptasi dengan berbagai situasi yang ditemukan dalam kehidupan seharihari. Bentuk pemahaman konsep yang memudahkan beradaptasi dengan lingkungan dan kehidupan sehari-hari antara lain kemampuan menafsirkan, menjelaskan, membandingkan, mencontohkan dan menyimpulkan.

Cara yang dapat dilakukan agar siswa mampu memahami konsep dengan baik yaitu dengan melibatkan siswa dalam kegiatan pembelajaran. Kegiatan dalam pembelajaran eksperimen yang dapat membantu siswa memahami konsep dengan baik adalah membimbing siswa membuat hasil pengumpulan data dalam berbagai representasi, misalnya dalam bentuk tabel, grafik, atau gambar.

Berdasarkan hasil wawancara dengan siswa, diketahui bahwa pemahaman siswa pada konsepkonsep elastisitas masih kurang. Kurangnya pemahaman siswa pada konsep elastisitas disebabkan kegiatan pembelajaran dan penyajian materi cenderung monoton menggunakan model ceramah, sedikit diskusi, dan berpusat pada guru sehingga siswa pasif dan hanya menerima materi yang disajikan guru. Selain itu, pembelajaran elastisitas belum menggunakan media yang dapat membantu siswa untuk memahami konsep.

Pembelajaran fisika yang menekankan siswa pada kemampuan penyelesaian matematis juga menyebabkan pemahaman kosep elastisitas siswa rendah. Siswa dilatih menyelesaikan masalahmasalah fisika dengan menggunakan rumus cepat tanpa melalui proses penyelesaian masalah secara kualitatif. Hal ini memicu siswa dalam menghafal rumus-rumus instan dan menerapkan untuk karakteristik soal-soal yang sama; sehingga siswa mampu menyelesaikan masalah fisika dengan tingkat kesulitan matematika tinggi, namun kesulitan untuk menyelesaikan masalah pemahaman konsep. 
Upaya peningkatan pemahaman konsep siswa dapat dilakukan dengan menggunakan media gambar yang dapat bergerak sehingga siswa dapat melakukan eksplorasi. Media pembelajaran tersebut dapat digunakan untuk melakukan pengukuran, pengumpulan data, dan analisis data dari hasi pengukuran (Ekawati, Haris \& Amin, 2015). Hidayat, Hakim, \& Lia (2019) menyatakan bahwa penggunaan media pelajaran dapat membantu siswa memahami konsep elastisitas lebih mudah. Salah satu media yang dapat digunakan dalam pembelajaran fisika adalah PhET Simulation. Media pembelajaran ini dapat mensimulasikan konsep abstrak sehingga siswa lebih mudah memahami konsep. Selain itu, PhET Simulation merupakan media pembelajaran yang interaktif, menarik, dan dapat membuat siswa bereksplorasi terhadap suatu materi. Gabungan model inkuiri terbimbing dan simulasi PhET diharapkan dapat membuat pemahaman konsep fisika siswa menjadi lebih baik. Oleh karena itu, perlu dilakukan penelitian dengan menerapkan model pembelajaran inkuiri terbimbing berbantuan simulasi PhET.

\section{METODE}

Metode yang digunakan dalam penelitian ini adalah kuasi eksperimen. Desain yang digunakan dalam penelitian ini adalah nonequivalent control group design dengan tipe posttest only control group. Populasi penelitian adalah seluruh kelas XI IPA di salah satu SMA kota Palembang. Teknik pengambilan sampel menggunakan cluster random sampling. Sampel penelitian terdiri atas kelas eksperimen dan kelas kontrol. Kelas eksperimen mendapat pembelajaran inkuiri berbantuan PhET, sedangkan kelas kontrol mendapat pembelajaran direct instruction. Sampel yang digunakan dalam penelitian ini adalah kelas XI IPA 3 sebagai kelas eksperimen dan kelas XI IPA 4 sebagai kelas kontrol. Desain penelitian ditunjukkan Tabel 1.

Tabel 1. Desain Penelitian

\begin{tabular}{ccc}
\hline Kelas & Perlakuan & Posstest \\
\hline Eksperimen & $\mathrm{X}$ & $\mathrm{O}$ \\
Kontrol & $\mathrm{Y}$ & $\mathrm{O}$ \\
\hline
\end{tabular}

Keterangan:

X: Model Inkuiri Terbimbing

Y: Model Direct Instruction

O: Posttest (Ali \& Asrori, 2014)

Instrumen yang digunakan dalam penelitian ini adalah instrumen tes pemahaman konsep yang berbentuk esai. Sebelum digunakan, instrumen divalidasi oleh ahli dan diujicobakan pada siswa. Validasi ahli bertujuan untuk mengetahui bahwa instrumen yang digunakan menggunakan kaedah bahasa Indonesia yang baik dan benar, tidak menggunakan bahasa ambigu, tidak mengandung kesalahan atau miskonsepsi, dapat dibaca dengan baik, dan tidak ada salah ketik. Berdasarkan pendapat ahli, soal dapat digunakan dan perlu 
direvisi untuk kesalahan pengetikan. Soal tes yang ambigu dan sulit dipahami oleh siswa direvisi sehingga siswa tidak salah persepsi dalam menjawab soal tersebut.

Ujicoba instrumen bertujuan untuk mengetahui validitas, reliabilitas, daya pembeda, dan tingkat kesukaran. Hasil ujicoba instrumen dapat diketahui bahwa tujuh soal valid dari 10 soal yang diujicobakan dengan reliabilitas 0,5 (kategori sedang). Dari tujuh soal valid tersebut, terdapat empat soal dengan tingkat kesukaran sedang, dua soal mudah dan satu soal sukar. Ketujuh soal tersebut digunakan dalam penelitian.

Analisis pemahaman konsep siswa dilakukan menggunakan uji-t. Sebelum melakukan uji-t, dilakukan prasyarat yaitu uji normalistas data. Jika terpenuhi prasyarat uji normalitas dan uji homogenitas maka dilakukan uji perbedaan ratarata dengan menggunakan uji-t. Jika uji prasyarat tidak terpenuhi maka analisis data menggunakan statistic non para metric yaitu uji Mann Witney.

\section{HASIL DAN PEMBAHASAN}

Data hasil posttest kelas eksperimen dan kelas kontrol disajikan pada Gambar 1. Berdasarkan Gambar 1 dapat diketahui bahwa hasil belajar kelas eksperimen lebih tinggi dibanding kelas kontrol. Tingginya hasil belajar kelas eksperimen disebabkan oleh pemahaman konsep siswa kelas eksperimen lebih baik dibanding kelas kontrol, baik secara keseluruhan maupun pada setiap indikator. Hasil ini hampir sama dengan penelitian Hidayat, Hakim \& Lia (2019) yang menunjukkan bahwa model inkuiri terbimbing dengan bantuan PhET dapat meningkatkan pemahaman konsep siswa.

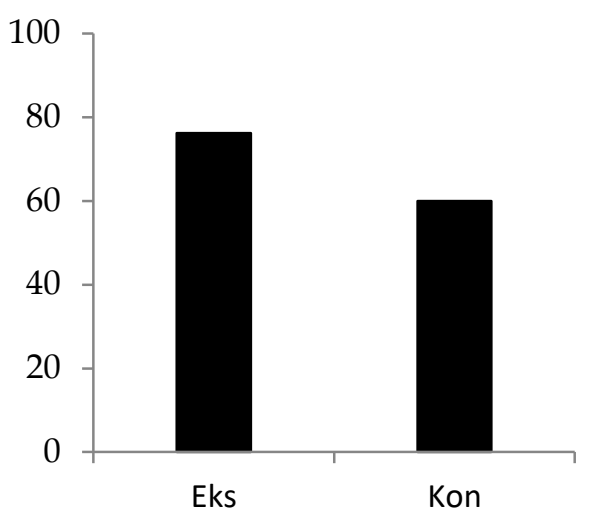

Gambar 1. Data Hasil Posttest Kelas Eksperimen dan Kelas Kontrol

Hasi belajar siswa juga dianalisis pada tiap indikator soal. Data hasil belajar siswa kelas eksperimen dan kelas kontrol untuk setiap indikator ditunjukkan pada Gambar 2.

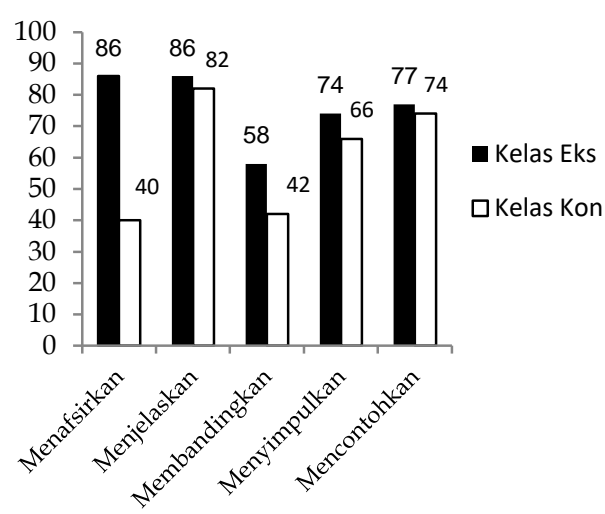

Gambar 2. Data Hasil Belajar Siswa Tiap Indikator 
Pemahaman konsep tertinggi siswa kelas eksperimen terdapat pada indikator menafsirkan dan menjelaskan. Kemampuan menafsirkan pada model inkuiri terbimbing dilatih melalui kegiatan membuat sketsa grafik untuk analisis data hasil percobaan. Pada proses pembelajaran, kemampuan menafsirkan dan menjelaskan lebih banyak muncul dalam penerapan model inkuiri terbimbing di kelas eksperimen. Indikator paling rendah di kelas kontrol terdapat pada indikator membandingkan karena pada kelas kontrol hanya terdapat satu kali latihan dan kegiatan penemuan untuk membandingkan nilai elastisitas bahan sehingga siswa masih belum terlatih dalam membandingkan dua besaran atau dua variabel yang berbeda maupun berbagai variasi perbedaan variabel.

Analisis data percobaan yang dilakukan siswa dimulai dengan mentabulasi hasil pengukuran menggunakan simulasi PhET. Tabulasi hasil percobaan dengan menggunakan PhET berupa data pertambahan panjang pegas dengan variasi massa benda yang digantung pada pegas. Pengambilan data perubahan panjang dilakukan dengan lima kali variasi massa benda. Data yang diperoleh kemudian dibuat grafik hubungan antara massa dan pertambahan panjang. Grafik tersebut merupakan kecenderungan persamaan garis lurus yang berasal dari titik asal. Berdasarkan grafik hubungan antara perubahan panjang pegas dan massa benda, siswa dilatih untuk menjeneralisasi persamaan hukum Hooke. Dengan demikian, siswa terlibat langsung dalam pembuatan grafik hubungan massa dan perubahan panjang pegas sehingga dapat mengubahnya dalam bentuk verbal.

Indikator menjelaskan dilatih dalam kegiatan diskusi dan pengambilan keputusan. Selama kegiatan diskusi, siswa dilatih untuk menggunakan bahasa sendiri dalam mengungkapkan temuan-temuan yang diperoleh dalam pembelajaran. Kegiatan diskusi juga meningkatkan rasa ingin tahu, sehingga siswa mencari berbagai informasi untuk dijadikan sumber belajar.

Hasil uji normalitas data posttest dengan taraf sigifikan $5 \%$ sebesar $0,177>0,05$ untuk kelas eksperimen dan 0,064 >0,05 untuk kelas control, sehingga dapat ditarik kesimpulan bahwa data yang didapatkan terdistribusi normal untuk kelas eksperimen maupun kontrol.

Uji hipotesis dengan taraf signifkansi $5 \%$ diperoleh nilai signifikansi sebesar $0,000<0,05$ sehingga dapat disimpulkan bahwa terdapat pengaruh yang signifikan antara model pembelajaran inkuiri terbimbing dan pemahaman konsep siswa. Penggunaan model inkuiri terbimbing pada kelas eksperimen memberikan ruang bagi siswa untuk menggali informasi lebih banyak melalui berpendapat dan bertukar informasi kepada teman kelompoknya (Susilawati, Huda, Saputo \& Khoiri, 2019). Selain itu, 
model pembelajaran inkuiri terbimbing menjadikan siswa lebih aktif dibanding kegiatan pembelajaran sebelumnya yang menggunakan model pembelajaran direct instruction. Setelah menggunakan model inkuiri terbimbing, siswa dapat melakukan kegiatan eksperimen yang membuat siswa terlibat langsung untuk menggali informasi yang belum siswa ketahui dan tidak hanya memperoleh informasi dari guru (Aeni, Supardi \& Kasmadi, 2017).

Berdasarkan hasil penelitian yang dilakukan, model pembelajaran inkuri terbimbing memberikan hasil pemahaman konsep yang lebih baik dibanding pembelajaran yang menerapakan model direct instruction. Hasil ini sesuai dengan penelitian Maladjuna, Saehana \& Syamsu (2017) yang menunjukkan bahwa model inkuiri terbimbing mampu memberikan pengaruh yang lebih baik terhadap pemahaman konsep siswa.

\section{KESIMPULAN}

Berdasarkan data hasil penelitian serta pembahasannya dapat disimpulkan pemahaman konsep siswa yang menggunakan model pembelajaran inkuiri terbimbing berbantuan PhET lebih baik dibanding siswa yang menggunakan model direct instruction. Pemahaman konsep tertinggi pada kelas eksperimen terdapat pada indikator menafsirkan dan menjelaskan. Pemahaman konsep tertinggi pada kelas kontrol terdapat pada indikator membandingkan.

\section{UCAPAN TERIMA KASIH}

Ucapan terima kasih disampaikan kepada program studi pendidikan fisika Universitas PGRI Palembang.

\section{DAFTAR PUSTAKA}

Abdurrozak, R., Jayadinata, A.K. \& Isrok'atun, 2016. Pengaruh Model Problem Based Learning terhadap Kemampuan Berargumentasi dan Hasil Belajar Siswa. Jurnal Pena Ilmiah. 4(2): 45-50.

Aeni, A., Supardi, S. \& \& Kasmadi, I., 2017. Keefektifan Pembelajaran Praktikum Berbasis Guided Inquiry Terhadap Keterampilan Laboratorium Siswa. Chemistry in Education, 6(1): 8-13.

Ali, M. \& Asrori, M., 2014. Metodologi Dan Aplikasi Riset Pendidikan, Jakarta: Bumi Aksara.

Anam, K., 2016. Pembelajaran Berbasis Inkuiri, Jakarta: Pustaka Pelajar. Arimbawa, P.A., Santyasa, I.W. \& Rapi, N.K., 2017. Strategi Pembelajaran Guru Fisika: Relevansi dalam Pengembangan Motivasi Belajar dan Prestasi Belajar Siswa. Wahana Matematika Dan Sains: Jurnal Matematika, Sains, Dan Pembelajarannya, 11(1): 43-60.

Ekawati, Y., Haris, A. \& Amin, B., 2015. Penerapan Media Simulasi Menggunakan PhET (Physics Education And Technology) 
Terhadap Hasil Belajar Fisika Peserta Didik Kelas X SMA Muhammadiyah Limbung. Jurnal Pendidikan Fisika Unismuh. 1(1): 35-48.

Hidayat, R., Hakim, L. \& Lia, L., 2019.

Pengaruh Model Guided

Discovery Learning Berbantuan Media Simulasi PhET Terhadap

Pemahaman Konsep Fisika Siswa. Berkala Ilmiah Pendidikan Fisika, 7(2): 97-104.

Kanginan, M. 2016. Fisika Untuk SMA/MA Kelas X., Bandung:

Erlangga.

Kusdiastuti, M., Harjono, A., Sahidu, H., \& Gunawan, G. 2017.

Pengaruh Model Pembelajaran Inkuiri Berbantuan

Laboratorium Virtual Terhadap Penguasaan Konsep Fisika Peserta Didik. Jurnal Pendidikan Fisika Dan Teknologi, 2(2): 85-96. Lewa, I.W.L., Susanto, H. \& Marwoto, P. 2017. Implementasi Model Pembelajaran Inkuiri Terbimbing Pada Siswa Sma. Jurnal Pendidikan Fisika Dan Teknologi, 7(2): 400-404.

Maladjuna, D.A., Saehana, S. \& Syamsu, S., 2017. Pengaruh Model Pembelajaran Inkuiri Terbimbing Terhadap Pemahaman Konsep Siswa pada Mata Pelajaran Fisika di SMP
Negeri 19 Palu. Jurnal Pendidikan Fisika Tadulako, 4(1): 30-36.

Nurhalimah, S.R., Suhartono, S. \& Cahyana, U., 2017. Pengembangan Media Pembelajaran Mobile Learning Berbasis Android pada Materi Sifat Koligatif Larutan. JRPK: Jurnal Riset Pendidikan Kimia, 7(2): 160-167.

Rahayu, S., 2017. Model Simulasi dalam Mata Kuliah Strategi Pembelajaran Fisika. Jurnal Pendidikan Fisika dan Teknologi, 1(2): 102-118.

Sani, R.A., 2019. Strategi Belajar Mengajar, Jakarta: Raja Grafindo Persada.

Sundaygara, C., Pratiwi, H.Y. \& Hudha, M.N., 2019. Pengembangan bahan ajar media pembelajaran fisika dengan pendekatan multi representasi untuk meningkatkan kemampuan pembuatan alat-alat praktikum calon guru fisika. Momentum: Physics Education Journal, 2(2): 86-93.

Susilawati et al., 2019. Pre-service teacher ideas about designing demonstration set in physics education program. Journal of Physics: Conference Series, 1170 (1): 012046. 